\title{
Question/Answer Congruence and the Semantics of wh-Phrases*
}

\author{
Ingo Reich \\ Universität Tübingen \\ ingo.reich@uni-tuebingen.de
}

\begin{abstract}
This paper is about the semantics of wh-phrases. It is argued that wh-phrases should not be analyzed as indefinites as, for example, Karttunen (1977) and many others have done, but as functional expressions with an indefinite core --their function being to restrict possible focus/background structures in direct or congruent answers. This will be argued for on the basis of observations made with respect to the distribution of term answers in well-formed question/answer sequences. This claim having been established, it will be integrated in a categorial variant of Schwarzschild's (1999) information-theoretic approach to F-marking and accent placement, and - second- - its consequences with respect to the focus/background structure of $w h$-questions will be outlined.
\end{abstract}

\section{Answers, Focus, and Background Deletion}

Since the work of Hermann Paul (1920) and M.A.K. Halliday (1967) it has been commonly assumed that in well-formed, i.e., congruent, question/answer sequences (Q/Asequences) there is a rather systematic correlation between the $w h$-question $Q$ and the focus/background structure (F/B-structure) of its direct (sentential) answers $A$, cf. (1).

(1) $A$ is a direct/congruent answer to $Q$, only if every constituent in $A$ that corresponds to a $w h$-phrase in $Q$ is focussed (i.e., F-marked).

This generalization can be illustrated by the Q/A-sequences given in (2).
a. Who likes John? [MARY] likes John, ...
b. Who likes whom? [MARY $]_{\mathrm{F}}$ likes $[\mathrm{JOHN}]_{\mathrm{F}}, \ldots$
c. What did Sandra say? Sandra said [that Mary kissed $\left.[\mathrm{JOHN}]_{\mathrm{F}}\right]_{\mathrm{F}}, \ldots$

In (2a) the constituent Mary corresponds to the wh-phrase who, and Mary has to be focussed; in (2b) Mary corresponds to who, John corresponds to whom, and both have to be focussed. Given that the generalization in (1) is in fact basically correct, then (2c) shows that the property of being focussed does not coincide with the property of being accented in a strict sense, but that a focussed and accented constituent may license an abstract focus (F-marking) on a larger constituent containing it. Dynamically speaking,

\footnotetext{
"The paper is submitted to a special issue of "Theoretical Linguistics", edited by Klaus von Heusinger and Kerstin Schwabe

1 As usual, accents are indicated by capitals.
} 
the focus on John (the 'focus exponent') in (2c) 'projects up to the that-clause' in a way to be specified.

Although tempting, the generalization given in (1) cannot be strengthened from 'only if' to 'if and only if,' since one always has to reckon with the presence of so-called 'contrastive topics,' cf. (3). In the following, however, the possibility of contrastive topics will be almost completely ignored. ${ }^{2}$
a. Whom do John and Mary like?
b. $[\mathrm{MARY}]_{\mathrm{F}}$ likes $[\mathrm{JOHN}]_{\mathrm{F}}$ and $[\mathrm{JOHN}]_{\mathrm{F}}$ likes $[\mathrm{SANDRA}]_{\mathrm{F}}$.

Another property of (1) worth mentioning is that it is a generalization about sentential answers. Typically, however, questions are not answered by sentential answers, but by 'short' or so-called 'term answers,' cf. (4) and (5).
a. Who likes John? Mary.
b. Who likes whom? Mary, John; ...
c. What did Sandra say? That Mary kissed John.
a. Whom do John and Mary like?
b. Mary, John and John, Sandra.

This immediately raises the question of whether, and --if so- in what way, sentential answers and term answers are related to each other. Apart from the obvious parallel between the F/B-structures of sentential answers in (2) and (3) and the term sequences in (4) and (5), there are good reasons to assume that the latter are derived from the former by some kind of elliptical process. To mention just two arguments, term answers and the respective wh-phrases have to agree in case, cf. (6), and term answers may occur in the form of reciprocals, cf. (7). Both phenomena, however, are known to be strictly local, confined more or less to the minimal clause they are contained in. ${ }^{3,4}$

Wen traf Hans? *Ein Mann. /*Eines Mannes. /*Einem Mann. / Einen Mann. Who met Hans? *[A man]-nom / *[A man]-gen /*[A man]-dat / [A man]-acc 'Who did Hans meet? A man.'

\section{Wem vertrauen Schröder und Blair? Einander. Whom trust Schröder and Blair? Each other. 'Who do Schröder and Blair trust? Each other.'}

The way term answers are derived from sentential ones seems to be quite straightforward: starting from a well-formed sentential answer everything is phonologically reduced that is not embedded in an F-marked node. Thus, this kind of elliptical process has to be conceived of as an instance of background deletion, and can be stated in a maximally theory neutral (and descriptive) manner as indicated in (8).

\footnotetext{
2 But cf. e.g. the discussion in Büring (1997), Krifka (1998), Reich (2001).

3 For further evidence, cf. e.g. Schwabe (1994), Reich (2001).

4 In the following, I will always switch to German data, if the point to be made can be better illustrated using German examples, or if the data is rather subtle.
} 


\section{Background deletion in Q/A-sequences (optional)}

Let $\langle Q, A\rangle$ be a well-formed $\mathrm{Q} / \mathrm{A}$-sequence and let the F/B-structure of (sentential) $A$ be of the form $\alpha_{0}\left[\beta_{0}\right]_{\mathrm{F}} \alpha_{1}\left[\beta_{1}\right]_{\mathrm{F}} \alpha_{2} \ldots\left[\beta_{\mathrm{n}-1}\right]_{\mathrm{F}} \alpha_{\mathrm{n}}$ (where $\mathrm{n} \geq 1, \alpha_{\mathrm{i}}, 0 \leq \mathrm{i} \leq \mathrm{n}$, possibly null), then $\mathrm{p}$-reduce $\alpha_{\mathrm{i}}$ for $0 \leq \mathrm{i} \leq \mathrm{n}: \chi_{0}\left[\beta_{0}\right]_{\mathrm{F}} \otimes_{1}\left[\beta_{1}\right]_{\mathrm{F}} \otimes_{2} \ldots\left[\beta_{\mathrm{n}-1}\right]_{\mathrm{F}} \otimes_{\mathrm{n}}$.

As recent research on ellipsis has shown, background deletion plays a crucial role in presumably all kinds of elliptical processes, and may thus be considered as a general strategy underlying elliptical phenomena in general. ${ }^{5}$ Typically, this process is further restricted by additional syntactic and/or semantic requirements like, for example, 'directionality requirements' in RNR-Constructions (cf. e.g. Klein 1993, Hartmann 1999) or 'correspondence requirements' in VP-ellipsis phenomena (cf. e.g. Fiengo \& May 1994, Merchant 1999). However, apart from the implemented maximality condition, background deletion in Q/A-sequences seems to be rather - but not completely- unrestricted (cf. Kuno 1982).

\section{The Problem}

Keeping this in mind, consider the discourse given in (9) (cf. Schwarzschild 1999:161).
(John drove Mary's red conVERtible.)
a. What did he drive before that?
b. He drove her $[\mathrm{BLUE}]_{\mathrm{F}}$ convertible.

As I will show below in some detail, 'standard' projection theories on F-marking like, for example, that in Selkirk (1996), as well as information-theoretic approaches like that developed in Schwarzschild (1999), predict - first - that the prenominal adjective blue in $(9 \mathrm{~b})$ is F-marked, and - second- that no other constituent is. However, given that the assumptions about the derivation of term answers made above are basically correct, the F/B-structure of the answer in (9b) together with the generalization in (8) predict that $(10 \mathrm{~b})$ is a well-formed term answer in the context of (10a). But in fact it is not. The correct term answer is that given in $(10 \mathrm{c})$-it is the whole constituent corresponding to the $w h$-phrase.

(10) a. What did he drive before that?

b. $\quad *[B L U E]_{\mathrm{F}}$.

c. Her $[\mathrm{BLUE}]_{\mathrm{F}}$ convertible.

5 Cf. e.g. Rooth (1992b), Klein (1993), Romero (1998), and Schwabe \& Zhang (2000).

6 Term answers of category VP need to contain the uninflected part of the verbal predicate:

(i) Was machte Peter? *Pete PAn $_{\mathrm{i}}$ [An ein FAHrad $\mathrm{t}_{\mathrm{i}} \mathrm{J}_{\mathrm{F}}$

What did Peter? *Peter beught $\left[\text { Anna a bike } \mathrm{t}_{\mathrm{i}}\right]_{F}$

'What did Peter do? Peter bought a bike for Anna.'

(ii) Was hat Peter gemacht? Pet [Anna ein FAHRrad gekauft $]_{F}$

What has Peter done? Peteras [Anna a bike bought $]_{F}$

'What has Peter done? Peter has bought a bike for Anna.'

As a consequence, term answers of category VP are confined to the perfective forms of tense in German. 
Actually, it turns out that this contrast is not restricted to the nominal domain, but can be observed with respect to the sentential and the verbal domain, too, cf. (11) and (12).

(11) (John said that he likes to drive conVERtibles.)

a. What else did he say?

b. $\quad *$ [OLDtimers $]_{\mathrm{F}}$.

c. That he likes to drive [OLDtimers $]_{\mathrm{F}}$.

(12) (Peter hat Anna ein CAbrio gekauft

'Peter bought a conVERtible for Anna')

a. Und was hat er sonst noch gemacht?

and what has he else Part done

'And what else did he do?'

b. Er hat $[\mathrm{SANdra}]_{\mathrm{F}}$ ein Cabrio gekauft. he has Sandra a convertible bought

'He bought a convertible for SANdra'

c. *SANdra.

d. SANdra ein Cabrio gekauft.

Again, it is the constituent corresponding to the wh-phrase that constitutes the term answer and not the constituent in focus. Thus, this data together with the generalization about the derivation of term answers stated in (8) strongly suggests that it is not only the prenominal adjective that is F-marked, but in fact the whole constituent corresponding to the $w h$-phrase. ${ }^{7}$ Moreover, it suggests that this effect is due to some property of the $w h$-phrases involved. This is what I will call the functional character of $w h$-phrases. The major claim I want to argue for in this paper is that this property has to be located in the semantics of wh-phrases.

Obviously, it may be immediately objected that this data just shows that the assumptions about the derivation of term answers made above are too simplistic and have to be revised or restricted in one way or another. The crucial point is, however, that I see no straightforward way of doing so without merely stating the facts; ${ }^{k}$ and even if someone came up with a proposal, (8) still seems to be the null hypothesis and is, therefore, the theoretically preferred option. Hence, I will assume from now on that the constituents corresponding to a wh-phrase are in fact F-marked. Then, obviously, the question emerges, why 'standard approaches' to F-marking do not permit this F-marker, and whether there is any straightforward and natural way of modifying (one of) them in such a way that they do.

Following a different line of argumentation, Drubig (1994) draws similar (although not identical) conclusions with respect to the F/B-structure of so-called 'negative contrastive constructions' like not ..., but ... in English or nicht ..., sondern ... in German. For further discussion, cf. Reich (2001).

8 Examples like (10) suggest that the derivation of term answers has to respect the 'minimal functional complex' containing the focus. This restriction may in fact lead to correct results in examples like (10), but it won't do so in more complex cases like (11) - cf. *Her BLUE convertible. vs. That he likes to drive her BLUE convertible.- or in cases where the term answer is constituted by a lexical projection, cf. (12). 


\subsection{The Problem within Projection Approaches}

First of all, let's have a look at so-called 'projection theories,' the most prominent representative of which is presumably Selkirk (1984, 1996). Selkirk (1996) assumes that F-marking is controlled by the set of rules given in (13) and (14).

(13) Basic Focus Rule

An accented word is F-marked.

(14) Focus Projection

a. F-marking of the head of a phrase licenses the F-marking of the phrase.

b. F-marking of an internal argument of a head licenses the F-marking of the head.

Now, reconsider Schwarzschild's example (9) in the light of (13) and (14). The prenominal adjective blue is accented; hence it is F-marked by the Basic Focus Rule (13). However, being an adjunct, it cannot license F-marking of the non-accented head of the DP, cf. (14b). Since there is no other candidate that could license F-marking of the head, it has to be concluded that the head is not F-marked. But since the head is not F-marked, F-marking of the DP isn't licensed either.

Is there a straightforward way of modifying this approach? As far as I can see, no. The crucial problem is that any mechanism that allows F-markers to project from prenominal adjectives to the DP containing them cannot prevent the F-marker from projecting to VP if the DP is an internal argument of the verbal head; i.e., the Q/Asequence in (15) would be predicted to be well formed in general, especially in an out of the blue utterance.

(15) a. What did John do?

b. *He [drove Mary's [RED] convertible].

\subsection{The Problem within Information-Theoretic Approaches}

The other prominent approach that can be traced back to the work of Arnim von Stechow (cf. von Stechow 1981), but became well known with the work of Schwarzschild (1999), assumes a more direct connection between the information-theoretic notion of being 'given' and F-marking. Schwarzschild (1999) provides us with two basic information-theoretic principles, the first stating that non-F-marked constituents must be GIVEN, cf. (16), the second being an instruction to F-mark as little as possible, cf. (17).

\section{GIVENness}

If a constituent is not F-marked, it must be GIVEN.

AVoIDF

Do not F-mark.

Contrary to Selkirk's conception, the existence of an F-marker is not due to a constituent being accented, but rather accenting is a consequence of F-marking. This is ensured by a constraint called FOC, cf. (18). The distinction between Foc-marked and Fmarked phrases, however, is not important for our purposes, since in all the relevant examples discussed so far each F-marked constituent is at the same time a Foc-marked constituent. 
A Foc-marked phrase contains an accent.

There are two more things to say. First, it has to be determined precisely what it means for a constituent to be GIVEN, cf. (19).

\section{Definition of GIVEN (partial, informal version)}

a. An utterance U counts as GIVEN iff it has a salient antecedent $A$ and modulo existential type-shifting, A entails the existential F-Closure of U.

b. Existential F-Closure of $U:=$ the result of replacing F-marked phrases in $\mathrm{U}$ with variables and existentially closing the result, modulo existential type shifting.

Second, it has to be emphasized that the constraints GIvenness, AvOIDF and FoC are organized in an optimality theoretic manner, i.e., one is allowed to violate constraints according to the partial order given in (20).

\section{Ranking ' $>$ ' ('overrules') of Constraints}

a. GIVENness $>$ AVOIDF

b. FOC $>>$ AVOIDF

Having introduced the most basic assumptions of Schwarzschild's approach to F-marking, I can now show why in the convertible example (9) the DP her [BLUE] $]_{F}$ convertible mustn't be F-marked: As Schwarzschild (1999:161) shows himself, the DP in question is GIVEN in the sense specified in (19), cf. (21), hence F-marking of the DP is optional; since F-marking is optional, it is ruled out by AvoIDF.

\section{John drove Mary's red convertible ENTAILS}
a. $\quad \exists X \exists P[P$ (her $X$ convertible $)] \quad \Rightarrow D P$ is given.
b. $\exists X \exists y[y$ drove her $X$ convertible $)] \quad \Rightarrow$ VP is given.
c. $\exists X[$ He drove her $X$ convertible $] \quad \Rightarrow S$ is given.

Again, the question to be answered is whether there is a straightforward way to modify this approach. This time the answer is 'yes, in principle.' The only reason why the DP mustn't be F-marked is a violation of AvoIDF." However, as is clear from (20), the constraint AVOIDF can be violated if there is another constraint that is ranked higher. Since neither GIVENness nor FoC will force F-marking on the DP, there must exist another, independently needed constraint that allows for violation of AvOIDF. In the following two sections it will be argued that there is in fact good evidence for the existence of a constraint with this property, a constraint that allows for the presence of (focus-sensitive) rhetorical relations.

\footnotetext{
9 Note that the assumption that the whole DP is F-marked does not influence the realization of the accent within the DP. This is simply, because this assumption results in embedding one Foc-phrase within another.
} 


\section{A Slightly Modified Hamblin Approach: Functional wh-Phrases}

\subsection{Questions and Answers}

Since it will turn out that one of the rhetorical relations to be licensed by this constraint is the Q/A-relation, the semantics of focus and the semantics of $w h$-interrogatives I am assuming need to be outlined. To this effect, consider the well-formed Q/A-sequence in (22).
a. What did John drive?
b. John drove [Mary's red conVERtible $]_{F}$.

Without any argument, I will adopt the structured meaning approach to F/B-structures as developed in von Stechow (1981) and Cresswell \& von Stechow (1982), i.e., the F/Bstructure in $(22 b)$, repeated as (23a), is represented as the structured proposition consisting of the focus 'Mary's red convertible' and the property 'being driven by John,' cf. (23b).

$$
\begin{aligned}
& \text { a. John drove [Mary's red conVERtible] } \\
& \text { b. }
\end{aligned}
$$

Following Hamblin's (1973) dictum that "a question sets up a choice-situation between a set of propositions, namely, those propositions that count as answers to it" and taking the insight into account that $\mathrm{F} / \mathrm{B}$-structures are at the heart of the Q/A-relation, it is absolutely straightforward to construe a question like (22a), repeated here as (24a), as denoting a set of structured propositions, cf. (24b) and more precisely (24c).

(24) a. What did John drive?

b. $\quad\{$ Mary's red convertible, $\lambda x$.John drove $x\rangle$,

〈Peter's Porsche, $\lambda x$.John drove $x\rangle, \ldots\}$

c. $\quad \lambda p \exists x\left[\right.$ thing $^{\prime}(x) \& \mathrm{p}=\langle x, \lambda y$.John drove $\left.y\rangle\right]$

Thus, $w h$-interrogatives are still taken to denote sets of possible answers; the notion of being a possible answer, however, is now relativized to possible F/B-structures.

\subsection{Wh-Phrases as Functional Expressions}

Of course, the propositions contained in the denotation of a wh-interrogative have to be structured independently. This is exactly what I take to be the task of $w h$-phrases. Concretely, I propose to analyze $w h$-phrases not as a (type-shifted) variant of indefinites like something, cf. (25a), but as primarily functional expressions with an indefinite core that shape the F/B-structure of possible answers, cf. (25b).

$$
\begin{aligned}
& \text { a. } \quad \text { Traditional': }(\text { what })=\lambda Q \lambda p \exists x\left[\text { thing }{ }^{\prime}(x) \& Q(x)(p)\right] \\
& \text { b. } \quad \text { Proposal: } \quad(\text { what }) '=\lambda Q \lambda p \exists P \exists x\left[\text { thing }^{\prime}(x) \& Q(P) \& p=\langle x, P\rangle\right]
\end{aligned}
$$

Given this, the well-formedness condition imposed on Q/A-sequences, as stated in (1) above, can be reduced to the simplest condition one can think of, namely the $\epsilon$-relation, cf. (26). ${ }^{11}$

10 Of course, modulo the treatment of contrastive topics. 
As far as the logical form and the interpretation of $w h$-interrogatives are concerned, the functional view on $w h$-phrases is in essence consistent with the 'traditional analysis' of wh-interrogatives within the generative framework (cf. e.g. von Stechow 1993), i.e., a wh-interrogative like (27a) will be analyzed on the level of Logical Form as indicated in $(27 b)$.

a. What did John drive?

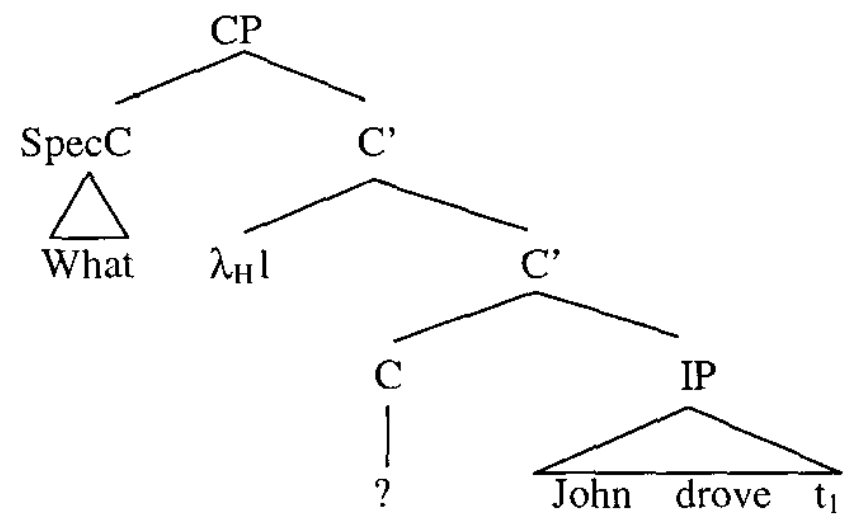

The wh-phrase what undergoes (overt) wh-movement (or an analogous set of operations like e.g. 'copy and delete,' cf. Chomsky 1995) and leaves a coindexed trace behind. Abstracting away from the role of variable assignments, the interpretation of the $\mathbb{P}$ John drove $t_{1}$ results in the proposition that John drove $x_{1}$. This proposition, then, is shifted by an 'interrogativator' '?' -located in C and interpreted as the function $\lambda q \lambda p[p$ $=q]$ - to the singleton set $\left\{\right.$ that John drove $\left.x_{1}\right\}$. Up to this point the interpretation of the logical form (27b) follows completely the 'traditional analysis;' contrary to the 'traditional analysis,' however, adjunction of the index 1 is not interpreted as 'common $\lambda$-abstraction' resulting in the function $\lambda x_{1}$. $\left\{\right.$ that John drove $\left.x_{1}\right\}$ from individuals to sets of propositions (cf. Heim \& Kratzer 1998), but as what I'd like to call 'Hamblinabstraction,' $\lambda_{\mathrm{H}}$, resulting in the function $\lambda_{\mathrm{H}} x_{1} \cdot\left\{\right.$ that John drove $\left.x_{1}\right\}$ from properties to truth values, i.e., in a set of properties. Informally speaking, the process of Hamblinabstraction $\lambda_{H}$ is equivalent to 'common $\lambda$-abstraction' within the set of propositions $\left\{\right.$ that John drove $\left.x_{1}\right\}$, i.e., $\lambda_{H} x_{1}$. $\left\{\right.$ that John drove $\left.x_{1}\right\}$ is basically equivalent to the set $\left\{\lambda x_{1}\right.$ that John drove $\left.x_{1}\right\} .^{1 "}$ The $w h$-phrase what, finally, singles out from this set the property 'being driven by John,' $\lambda x_{1}$.that John drove $x_{1}$, and builds the set of structured propositions consisting of all and only those structured propositions $\langle u, \lambda y$.John drove $y$, where $u$ is an individual that satisfies the restriction of the $w h$-phrase involved. This is exactly the intended result.

1 As far as I know, Hamblin (1973) was the first to make crucial use of what I call 'Hamblinabstraction' within his set-based model for natural language interpretation. Rooth (1985) and others following him, referred to Hamblin-abstraction in modeling the semantics of 'association with focus,' although on a different level of interpretation. It should be mentioned that the use of Hamblinabstraction presupposes a formal language that allows for expressions that denote functions from variable assignments to 'common denotations,' i.e., a language like the one developed in Montague (1970). For a similar model as well as a precise definition of Hamblin abstraction, the reader is referred to Reich (2001). 


\section{Integration into an Information-Theoretic Approach}

\subsection{Rhetorical Relations and the Restriction RHET-REL}

\subsubsection{The Rhetorical Relation answer}

Actually, my claim above that the answer (23a) denotes a structured proposition, was a bit too simplifying. The structured meaning approach - at least in its standard formulation - is a focus movement approach and the movement of the focus has to be triggered somehow. ${ }^{12}$ In the spirit of Jacobs (1984), I assume therefore that focus movement is always triggered by an operator, in case of so-called 'free foci' by a rhetorical relation, and in the special case of answers by a rhetorical relation that I'd like to dub answer. The rhetorical relation answer is a two-place relation that first binds the focus (the foci) in the answer and thus triggers the generation of a structured proposition, cf. (28), ${ }^{13}$ second introduces a variable $\Gamma$ ranging over sets of structured propositions and referring anaphorically to the contextually salient question, cf. (28b),

$$
\begin{aligned}
& \text { a, answer }\left[\mathrm { F } \left[\text { John drove }_{\text {Mary's red conVERtible } \left.\left.]_{\mathrm{F}}\right]\right]}\right.\right. \\
& \text { b. answer }(\Gamma,(\text { Mary's red convertible, } \lambda x \text {.John drove } x\rangle)
\end{aligned}
$$

and, third, checks whether this structured proposition is a possible answer to the question, i.e., whether it is an element of the question's denotation, cf. (29).

$$
\llbracket \text { answer }(Q, A) \rrbracket=1 \text { iff } \llbracket A \rrbracket \in \llbracket Q \rrbracket \text {. }
$$

Now, everything is available to systematically coerce F-marking of the constituents corresponding to $w h$-phrases. One just has to introduce an additional constraint on $\mathrm{F}$ marking that allows for the presence of the focus-sensitive rhetorical relation answer -I call it RHET-REL (RHETorical-RELation), cf. (30a) - and to give it priority over the constraint AVOIDF introduced by Schwarzschild (1999), cf. (30b).

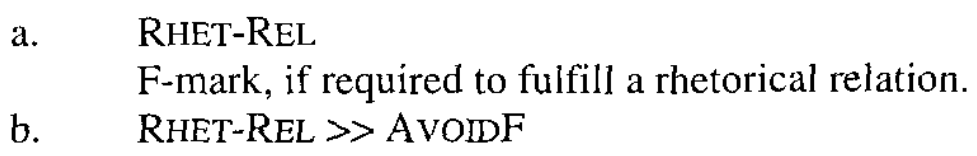

The well-formedness condition of $\mathrm{Q} / \mathrm{A}$-sequences thus turns out to follow directly from the interplay of the semantics of focus, the semantics of wh-constructions, and the semantics/pragmatics of the rhetorical relation answer, licensed by the constraint RHET-REL overruling AVOIDF.

12 It is a well-known problem that, in general, focus movement leads to the violation of island constraints, cf. e.g. the discussion in von Stechow (1991). In Reich (2001), however, it is argued that there is an independently justified variant of the structured meaning approach that substitutes focus binding for focus movement, and thus avoids the problem of violating island constraints. However, to keep things simple, I will stick to the movement approach for the remainder of the paper.

13. In fact, I am assuming that any rhetorical relation has to behave focus-sensitively. It may turn out that this requirement is too strict, but nevertheless it seems to constitute a reasonable methodological guideline. 


\subsubsection{The Rhetorical Relation contrast}

It should be emphasized that the assumption of an additional constraint RHET-REL is in fact independently motivated by examples involving so-called 'contrastive focus,' cf. e.g. the German data in (31).
a. Anna wird Alex zur Party einladen.
Anna will Alex to the party invite
'Anna will invite Alex to the party'
b. Ja, sie wird $[\mathrm{ALEX}]_{\mathrm{F}}$ einladen. Aber leider nicht [PEter $]_{\mathrm{F}}$.
Yes, she will $[\mathrm{ALEX}]_{\mathrm{F}}$ invite. But unfortunately not $[\mathrm{PEter}]_{\mathrm{F}}$.
'Yes, she will invite ALEX. But unfortunately, she won't invite PEter.'

According to the definition of GIVEN above, every constituent of sie wird Alex einladen in ( $31 \mathrm{~b}$ ) is GIVEN in the context of (31a). Since they are all GIVEN, none of them has to be F-marked (GIVENness); since none of them has to be F-marked, F-marking is forbidden by AvOIDF. The constituent Alex, however, does carry an accent, and, therefore, has to be F-marked. ${ }^{14}$ This, again, raises the question of what it is that overrules the constraint AvoIDF and licenses F-marking of the constituent Alex.

The answer I want to argue for is that the possibility of F-marking the constituent Alex is due to the presence of a rhetorical relation contrast binding "contrastive foci.' This in turn raises the question of how to define such a rhetorical relation. To see this, consider, the following examples typically being discussed under the notion 'contrastive focus' (cf. e.g. Rochemont 1986, Rooth 1992a):
a. [An [AMERican $]_{\mathrm{F}}$ farmer] met [a [CaNAdian $]_{\mathrm{F}}$ farmer].
b. John is neither $\left[[E A g e r]_{F}\right.$ to please $]$, nor $\left[[E A s y]_{F}\right.$ to please $]$, nor $\left[[C E R t a i n]_{F}\right.$ to please $]$.
c. $\left[[\mathrm{JOHN}]_{\mathrm{F}}\right.$ hit $\left.[\mathrm{BILL}]_{\mathrm{F}}\right]$ and then $\left[[\mathrm{HE}]_{\mathrm{F}}\right.$ hit $\left.[\mathrm{HIM}]_{\mathrm{F}}\right]$

Structurally, the examples cited in (32) all have one property in common: each of them contains at least two (maximal) constituents of the same category (DP, VP, or S) that differ in focus, but are identical in background. In (32a), for example, the DP an [AMERican] $]_{F}$ farmer is contrasted with the DP a [CaNAdian] $F$ farmer and vice versa, the focus simply serving the purpose of ensuring comparability on the one hand and distinctiveness in denotation on the other hand. I conclude from this data that the rhetorical relation contrast may adjoin at LF at any constituent (quite similar to Rooth's 1992a operator $\sim \Gamma$ ), but needs to bind at least one focus in its scope. (32a), for example, is represented at the level of LF as (33a), and interpreted as (33b).

$$
\begin{aligned}
\text { a. } & {\left[\text { contrast }\left[\mathrm{F}\left[\text { an }[\text { AMERican }]_{\mathrm{F}} \text { farmer }\right]\right]\right] \text { met } } \\
\text { b. } & {\left[\text { contrast }\left[\mathrm{F}\left[\text { a }[\text { CaNAdian }]_{\mathrm{F}} \text { farmer }\right]\right]\right] } \\
& \text { met'(contrast }(\langle\text { American, } \lambda X \text {.an } X \text { farmer }\rangle), \\
& \text { contrast }(\langle\text { Canadian, } \lambda X \text {.an } X \text { farmer }\rangle))
\end{aligned}
$$

\footnotetext{
14 The accent observed is definitely not a default accent in all-given utterances, for in German the default accent in all-given utterances is typically realized on the inflected part of the predicate, cf. Reis (1989).
} 
As far as truth-conditions are concerned, contrast is simply vacuous, cf. (34b); contrast presupposes, however, the presence of a contextually salient LF-constituent that differs in focus, but matches the background of the structured meaning in its scope, cf. $(34 b))^{15}$

a. $\quad \operatorname{contrast}(\langle\alpha, \beta\rangle)=\beta(\alpha)$;

b. $\quad$ contrast $(\langle\alpha, \beta\rangle)$ is defined iff there exists a contextually salient LFconstituent $\gamma,\left[\gamma \rrbracket=\left\langle\alpha^{\prime}, \beta^{\prime}\right\rangle\right.$, such that $\alpha \neq \alpha^{\prime}$, but $\beta=\beta^{\prime}$.

Definition (34) together with the constraint RHET-REL on F-marking thus does not only account for the specifics of the F/B-structures in examples like (31) and (40), but also for the specific interpretational effect -contrastiveness - triggered by their use.

Having defined the rhetorical relation contrast, we are now in the position to give a fully explicit account of Schwarzschild's convertible example (9), repeated here as (35) for convenience.
(John drove Mary's RED convertible.)
a. What did he drive (before that)?
b. (Before that,) He drove [her $[\mathrm{BLUE}]_{\mathrm{F}}$ convertible $]_{\mathrm{F}}$.
c. (Before $\left[\text { her }[B L U E]_{\mathrm{F}} \text { convertible }\right]_{\mathrm{F}}$.

In section 3 it has been argued that the $w h$-interrogative (35a) denotes the set $\{\langle u, \lambda x$. that John drove $x\rangle ; u$ is a driveable object $\}$ of structured propositions. Consequently, any declarative that is meant to answer the question (35a) necessarily needs to be Fmarked on the constituent corresponding to the wh-phrase what in (35a). Although this constituent is GIVEN in the relevant sense, and thus F-marking should be suppressed by AvOIDF, the F-marker is licensed by the constraint RHET-REL, when it is bound by the rhetorical relation answer; the focus on the constituent blue constitutes a symmetric (or asymmetric) contrastive focus that is bound by the rhetorical relation contrast. Altogether, both the sentential answer in (35b) and the term answer in (35c) are represented as (36a) on the level of Logical Form, and they are interpreted as indicated in (36b).
a. answer $\left[\mathrm{F}\left[\mathrm{He}\right.\right.$ drove [contrast $[\mathrm{F} \text { [her [blue }]_{\mathrm{F}}$ convertible]] $\left.\left.\mathrm{F}\right]\right]$
b. $\quad$ answer $(\Gamma,\langle$ contrast $(\langle$ blue, $\lambda X$.her $X$ convertible $\rangle), \lambda x$. he drove $x\rangle)$

On the basis of the definitions of the rhetorical relations answer and contrast, as well as the generalization about the derivation of term answers, (35b) and (35c) are correctly predicted to be well-formed answers in the context of (35a).

\subsection{Functional expressions and the restriction FuNCE}

Finally, I'd like to outline an important consequence of the functional view on $w h$ phrases for the F/B-structure of $w h$-interrogatives. It is well known that $w h$-phrases in

15 It should be noted that the definition of contrast in (34) does not directly capture the existence of asymmetric contrastive foci. As far as I can see, however, there is in principle no problem to generalize (34) in such a way that asymmetric contrastive foci can be accounted for, too. 
German (at least in simple wh-interrogatives) are typically unaccented, cf. (37a) vs. (37b), although they do not constitute GIVEN information in a strict sense.

(37) (out of the blue)
a. Wer hat (eigentlich) SANdra eingeladen?
Who has (anyway) SANdra invited?
'Who invited SANdra, anyway?'
b. *WER hat (eigentlich) SANdra eingeladen?
WHO has (anyway) SANdra invited?
'WHO invited SANdra anyway?'

This does not mean, however, that they never carry any accent. But if they do, this has —in general- an additional pragmatic effect: either the question becomes more emphatic, cf. (38a) and (38b), or accenting triggers a 'disputational' implicature (the existential implicature is called into question), cf. (38a) and (38c), or it correlates with an echo-reading, cf. (39).

(38) a. Heute koche ich mal wieder.

Today cook I Particle again

'I'll do the cooking again today.'

b. Schön. Und WAS kochst du?

Good. And WHAT cook you

'Good. And WHAT are you going to cook?'

c. Und WAS willst du kochen?

And WHAT want you cook

'And WHAT do you want to cook?'

(39) a. Peter hat gestern Sushi gegessen.

Peter has yesterday Sushi ate

'Yesterday, Peter ate Sushi.'

b. WAS hat Peter gestern gegessen?

WHAT has Peter yesterday ate

'WHAT did Peter eat yesterday?'

As Reis (1989) points out the most straightforward way to account for this data is to assume that, in general, wh-phrases in German are simply not F-marked. This fully accords with the observation made in Rosengren (1991) that, in German, the F/Bstructures of $w h$-interrogatives seem to be subject to exactly the same regularities as the F/B-structures in declaratives.

However, when having a look at comparative evidence this assumption is rather surprising; in Hungarian, for example, $w h$-phrases have to move into a distinguished focus position, cf. (40). ${ }^{16}$
Nem tudtuk
hogy Mari mit
tett az asztalra
not know-1.Pl. that Mary what-Acc laid Art table-on
'We don't know, what Mary laid on the table.'

16 This has been argued for extensively in Horvath (1986). 
Moreover, Ladd (1996:171) reports that in Turkish, a wh-in-situ language, wh-phrases even need to be accented, cf. (41).

(41) Halil'e NE verdiniz

Halil WHAT you-gave

'What did you give to Halil?'

Obviously, this data rather suggests that $w h$-phrases are focussed than that they are not. But given that the functional view on wh-phrases is basically correct, this data may be accounted for in a rather natural way: whereas the property of structuring propositions is part of the lexical semantics of wh-phrases in German (and English) - and thus whphrases in German (and English) have to be conceived of as functional elements- $w h$ phrases in Turkish seem to lack exactly this property - and thus have to be considered as non-functional in this respect-; since, however, for reasons of Q/A-congruence, the propositions in the question's denotation need to be structured, this task is taken over by a genuine syntactic mechanism, namely focussing.

Actually, in German and English wh-phrases are not the only expressions that behave in such a way. Similar observations can be made i.a. with respect to focus particles, negation, or sentential adverbials, cf. (42).

(42) a. John only introduced BILL to Mary.

b. John did not introduce BILL to Mary, but JOHN.

c. Unfortunately, John introduced BILL to Mary.

This parallel behavior shows that the prima facie peculiar behavior of $w h$-phrases simply mirrors their membership in the class of functional expressions: functional expressions are always considered to be given, for their primary function is not to add new information to a context, but to systematically operate on 'old information.' Within Schwarzschild's approach to F-marking this behavior can be captured by introducing a further constraint, FUNCE (FunCtional Expressions), that rules out F-marking of functional expressions, cf. (43a). ${ }^{17}$ Obviously, FunCE must be able to overrule GIVENness, cf. (43b).
a. FUNCE
Do not F-mark functional expressions.
b. FUNCE $>>$ GIVENness
c. RHET-REL $\gg$ FUNCE

Furthermore, giving the constraint RHET-REL priority over the constraint FUNCE, cf. (43c), allows the pragmatic effects triggered by focussing functional expressions to be derived from the presence of covert rhetorical relations, e.g. the rhetorical relation contrast.

17 Note that FUNCE allows for F-marking wh-phrases in Turkish, cf. the discussion above. 


\section{Summary}

On the basis of the assumption that term answers are derived from sentential ones by eliding their background, I argued that $w h$-phrases should be considered as functional expressions that shape the F/B-structure of possible answers. I therefore proposed to treat $w h$-interrogatives as denoting sets of structured propositions and to derive the wellformedness conditions on $\mathrm{Q} / \mathrm{A}$-sequences from the interaction of the semantics of $w h$ questions, the semantics of $\mathrm{F} / \mathrm{B}$-structures and the semantics/pragmatics of rhetorical relations. To coerce F-marking of the constituents corresponding to a wh-phrase, I proposed to extend Schwarzschild's approach to F-marking by an additional constraint called RHET-REL that allows for violations of AvOIDF. Finally, I showed that the assumption that $w h$-phrases are functional expressions allows to consider their peculiar behavior with respect to accenting as an instance of a more general phenomenon that can be captured by an independently needed constraint FunCE. The proposed extension of Schwarzschild's approach can be summarized as follows:
a. RHET-REL
F-mark, if required to fulfill a rhetorical relation.
b. FUNCE
Do not F-mark functional expressions.
c. Extending ' $>$ ':
(i) RHET-REL $>>$ AVOIDF
(ii) FuncE $>>$ GIVENness
(iii) RHET-REL $>$ FUNCE.

Finally, it should be pointed out that the mechanics introduced so far need to be generalized to complex wh-phrases like whose mother or how many apples; this, however, is another — complex - story (cf. Reich 2001).

\section{References}

Büring, D. (1997): The Meaning of Topic and Focus. The 59th Street Bridge Accent. London; New York. Chomsky, N. (1995): The Minimalist Program. Cambridge, Mass.

Cresswell, M.J.; von Stechow, A. (1982): De Re Belief Generalized. Linguistics and Philosophy 5, 503535.

Drubig, H. B. (1994): Island Constraints and the Syntactic Nature of Focus and Association with Focus. Arbeitspapiere des Sonderforschungsbereichs 340, Nr. 51. Tübingen/Stuttgart.

Fiengo, R.; May, R. (1994): Indices and Identity. Cambridge, Mass.

Halliday, M.A.K. (I967): Notes on Transitivity and Theme in English (Part II). Journal of Linguistics 3, 199-244.

Hamblin, C. L. (1973): Questions in Montague English. Foundations of Language 10, 4 1-53.

Hartmann, K. (1999): Background Matching in Elliptical Coordination. In: Schwabe, K. et al. (eds.) (1999): Ellipsis and Information Structure. Berlin. (Collection of Handouts presented at the Workshop "Ellipsis and Information Structure"' November 6-7, ZAS Berlin.)

Heim, I.; Kratzer, A. (1998): Semantics in Generative Grammar. Oxford.

Horvath, J. (1986): FOCUS in the Theory of Grammar and the Syntax of Hungarian. Dordrecht.

Jacobs, J. (1984): Funktionale Satzperspektive und Illokutionssemantik. Linguistische Berichte 91, 25-58.

Jacobs, J. et al. (eds.) (1993): Syntax - An International Handbook of Contemporary Research. Berlin; New York.

Karttunen, L. (1977): Syntax and Semantics of Questions. Linguistics and Philosophy 1, 3.44. 
Klein, W. (1993): Ellipsis. In: Jacobs, J. et al. (eds.) (1993): Syntax - An International Handbook of Contemporary Research. Berlin; New York, 763-799.

Krifka, M. (1998): Scope Inversion under the Rise-Fall Contour in German. Linguistic Inquiry 29, 75 112.

Kuno, S. (1982): Principles of Discourse Deletion - Case Studies from English, Russian and Japanese. Journal of Semantics 1, 61-93.

Ladd, D.R. (1996): Intonational Phonology. Cambridge.

Merchant, J. (1999): E-Givenness vs. LF-Identity in Ellipsis. In: Schwabe, K. et al. (eds.) (1999): Ellipsis and Information Structure. Berlin. (Collection of Handouts presented at the Workshop "Ellipsis and Information Structure" November 6-7, ZAS Berlin.)

Montague, R. (1970): Universal Grammar. Theoria 36, 373-398.

Paul, H. (1920): Prinzipien der Sprachgeschichte. Halle. 5. Auflage.

Reich, I. (2001): Zur Kongruenz von Frage und Antwort im Deutschen. Dissertation, Universität Tübingen.

Reis, M. (1989): Exkurs zu "W-Interrogativsätze und w-Echo-Fragen: Satzmodus und Fokus-Hintergrund-Gliederung". Ms., Universität Tübingen.

Rochemont, M.S. (1986): Focus in Generative Grammar. Amsterdam.

Rooth, M. (1985): Association with Focus. Ph.D. thesis, MIT.

Rooth, M. (1992a): A Theory of Focus Interpretation. Natural Language Semantics 1, 75-116.

Rooth, M. (1992b): Ellipsis Redundancy and Reduction Redundancy. In: Berman, S.; Hestvik, A. (eds.): Proceedings of the Stuttgart Ellipsis Workshop. Arbeitspapiere des Sonderforschungsbereichs 340, Nr. 29. Tübingen/Stuttgart.

Romero, Maribel (1998): Focus and Reconstruction Effects in wh-Phrases. Ph.D. thesis. University of Massachusetts, Amherst.

Rosengren, I. (1991): Zur Fokus-Hintergrund-Gliederung im Deklarativsatz und im w-Interrogativsatz. In: Reis, M.; Rosengren, I. (eds.): Fragesätze und Fragen. Tübingen. 175-200.

Schwabe, K. (1994): Syntax und Semantik situativer Ellipsen. Tübingen.

Schwabe, K. et. al. (eds.) (1999): Ellipsis and Information Structure. Berlin. (Collection of Handouts presented at the Workshop "Ellipsis and Information Structure"' November 6-7, ZAS Berlin.)

Schwabe, K.; Zhang, N. (eds.) (2000): Ellipsis in Conjunction. Tübingen.

Schwarzschild, R. (1999): GIVEnness, AvoIDF and Other Constraints on the Placement of Accent. Natural Language Semantics 7, 141-177.

Selkirk, E. O. (1984): Phonology and Syntax: The Relation between Sound and Structure. Cambridge, Mass.

Selkirk, E. O. (1996): Sentence Prosody: Intonation, Stress, and Phrasing. In: Goldsmith, J.A. (ed.): The Handbook of Phonological Theory. London.

von Stechow, A. (1981): Topic, Focus and Local Relevance. In: Klein, W.; Levelt, W. (eds.): Crossing the Boundaries in Linguistics. Dordrecht. 95-130.

von Stechow, A. (1991): Current Issues in the Theory of Focus. In: von Stechow, A.; Wunderlich, D. (eds.) (1991): Semantics - An International Handbook of Contemporary Research. Berlin.

von Stechow, A. (1993): Die Aufgaben der Syntax. In: Jacobs, J. et al. (eds.) (1993): Syntax - An International Handbook of Contemporary Research. Berlin; New York, 1-88. 